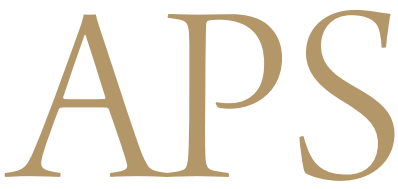

Archives of Plastic Surgery

\title{
Lower Lip Reconstruction after Wide Excision of a Malignancy with Barrel-Shaped Excision or the Webster Modification of the Bernard Operation
}

\author{
Hyung Joon Seo, Seong Hwan Bae, Su Bong Nam, Soo Jong Choi, Joo Hyoung Kim, \\ Jae Woo Lee, Yong Chan Bae \\ Department of Plastic and Reconstructive Surgery and Biomedical Research Institute, Pusan National University School of Medicine, \\ Busan, Korea
}

Background Because there are numerous methods for reconstruction of the lower lip, it is not easy to choose the optimal method. In choosing the surgical method for lower lip reconstruction, we obtained acceptable outcomes based on our treatment strategy, which included either a barrel-shaped excision or the Webster modification of the Bernard operation. We report on the surgical outcomes based on our treatment strategy.

Methods This study included 26 patients who underwent lower lip reconstructive surgery from September 1996 to September 2010. The operation was done using either a barrelshaped excision or the Webster modification, considering the location of the defect, the size of the defect, and the amount of residual tissue on the lateral side of the vermilion after excision. Results In our series, 3 patients underwent a single barrel-shaped excision, and nine patients underwent a double barrel-shaped excision. In addition, the unilateral Webster modification was performed on in 6 patients, and there were eight cases of bilateral Webster modification. All of the patients except one were satisfied with the postoperative shape of the lip. In one case both recurrence and dehiscence occurred. One patient had a good postoperative lip shape, but had difficulty wearing a denture, and also underwent commissuroplasty. Furthermore, there were two patients who complained of drooling, and 4 with paresthesia.

Conclusions A soft tissue defect resulting from wide excision of a lower lip malignancy can be successfully reconstructed using only one of two surgical methods: the barrel-shaped excision or the Webster modification of the Bernard operation.

Keywords Lip / Facial neoplasms / Reconstructive surgical procedures
Correspondence: Yong Chan Bae Department of Plastic and Reconstructive Surgery, Pusan National University School of Medicine, 179 Gudeok-ro, Seo-gu, Busan 602-739, Korea Tel: $+82-51-240-7273$ Fax: +82-51-243-9405 E-mail: baeyc2@hanmail.net

This work was supported for two years by a Pusan National University Research Grant.

This article was presented at the 69th Congress of the Korean Society of Plastic and Reconstructive Surgeons on November 11-13, 2011, in Seoul, Korea.

No potential conflict of interest relevant to this article was reported.

Received: 4 Oct 2012 • Revised: 17 Dec 2012 • Accepted: 18 Dec 2012

pISSN: 2234-6163 • elSSN: 2234-6171 • http://dx.doi.org/10.5999/aps.2013.40.1.36 • Arch Plast Surg 2013;40:36-43

\section{INTRODUCTION}

Surgical treatments for malignant neoplasms occurring on the lower lip are performed in order to minimize recurrence and to obtain satisfactory functional and aesthetic outcomes. In lower lip reconstruction, however, there are more than 200 surgical techniques. Besides, the operative methods should be determined considering various factors such as the location and size of the lesion and the range of resection. Therefore, it is difficult for plastic surgeons to select the optimal reconstruction method [1]. 
Generally, in cases of small lesions, primary closure can be performed synchronously with excision. Several types of surgical techniques, including V-shaped resection, $\mathrm{W}$-shaped resection, flared W-plasty, and barrel-shaped excision, can be applied to these cases. Among them, barrel-shaped excision has been used most frequently [2]. On the other hand, the Webster modification of the Bernard operation can be performed without a secondary procedure or commissuroplasty, which has the advantages of preserving the motor and sensory functions of the lip and also of providing satisfactory cosmetic outcomes of the reconstruction of the vermilion by using the oral mucosa. Therefore, this surgical treatment can be used as a first-line of choice for large defects, for which primary closure could not be performed following a resection $[3,4]$.

We had assumed that we could obtain an adequate outcome if we applied only one of two surgical methods, the barrel-shaped excision or the Webster modification of the Bernard operation, for lower lip reconstruction following wide excision of the malignant neoplasm.

As mentioned above, we applied either a barrel-shaped excision or the Webster modification of the Bernard operation to all of the patients with a lower lip malignancy. In this report, we present the outcomes of the surgeries that were based on our treatment strategy.

\section{METHODS}

\section{Patients}

This study included 26 patients who underwent lower lip reconstructive surgery from September 1996 to September 2010 (Table 1). All of the patients underwent either a barrel-shaped excision or the Webster modification of the Bernard operation. There were three patients with basal cell carcinoma and 23 with squamous cell carcinoma. There were also three patients that presented with recurred squamous cell carcinoma after being treated at a local medical center, and therefore visited our hospital. The follow-up period ranged from one to twelve years. Most of the patients underwent imaging studies including neck computed tomography (CT) and magnetic resonance imagining (MRI) before. Two patients, who were suspected of having cervical lymph node involvement, were referred to the Department of Otorhinolaryngology of our hospital. Thus, they concomitantly underwent neck lymph node dissection. The postoperative follow-up was performed during outpatient visits. The following factors were monitored: cosmetic outcomes, the patients' level of satisfaction, recurrence of the malignant mass, metastasis, and

\section{Table 1. Summary of the patient characteristics}

\begin{tabular}{|c|c|c|c|c|c|c|c|}
\hline Case & Age & Sex & $\begin{array}{l}\text { Recurred } \\
\text { case }\end{array}$ & Diagnosis & Surgical method & $\begin{array}{l}\text { Cancer cell (+) } \\
\text { at first biopsy }\end{array}$ & $\begin{array}{c}\text { Neck } \\
\text { dissection }\end{array}$ \\
\hline 1 & 88 & $\mathrm{~F}$ & & SCC & Barrel-shaped, double & & \\
\hline 2 & 83 & M & Yes & SCC & Webster, unilateral & & \\
\hline 3 & 74 & $\mathrm{~F}$ & Yes & SCC & Webster, bilateral & & \\
\hline 4 & 82 & $M$ & & SCC & Webster, bilateral & & \\
\hline 5 & 72 & M & & SCC & Barrel-shaped, double & & \\
\hline 6 & 71 & M & & $\mathrm{BCC}$ & Barrel-shaped, single & & \\
\hline 7 & 61 & M & & SCC & Barrel-shaped, single & & \\
\hline 8 & 90 & M & & SCC & Barrel-shaped, double & & \\
\hline 9 & 79 & $\mathrm{~F}$ & & SCC & Webster, bilateral & & \\
\hline 10 & 61 & M & & SCC & Webster, bilateral & & \\
\hline 11 & 45 & M & & SCC & Webster, unilateral & & \\
\hline 12 & 71 & $\mathrm{~F}$ & & SCC & Webster, bilateral & Yes & \\
\hline 13 & 76 & M & Yes & SCC & Webster, bilateral & Yes & \\
\hline 14 & 63 & $\mathrm{~F}$ & & SCC & Barrel-shaped, double & & \\
\hline 15 & 82 & $\mathrm{~F}$ & & SCC & Barrel-shaped, double & & \\
\hline 16 & 64 & M & & SCC & Barrel-shaped, double & & \\
\hline 17 & 47 & M & & SCC & Barrel-shaped, single & & \\
\hline 18 & 76 & $\mathrm{~F}$ & & SCC & Webster, bilateral & Yes & \\
\hline 19 & 57 & $\mathrm{~F}$ & & $\mathrm{BCC}$ & Barrel-shaped, double & & \\
\hline 20 & 67 & M & & $\mathrm{BCC}$ & Webster, unilateral & & \\
\hline 21 & 77 & M & & SCC & Webster, unilateral & & Yes \\
\hline 22 & 45 & M & & SCC & Webster, unilateral & & Yes \\
\hline 23 & 87 & $\mathrm{~F}$ & & SCC & Webster, unilateral & & \\
\hline 24 & 63 & M & & SCC & Webster, bilateral & Yes & \\
\hline 25 & 49 & M & & SCC & Barrel-shaped, double & & \\
\hline 26 & 43 & M & & SCC & Barrel-shaped, double & & \\
\hline
\end{tabular}


Fig. 1. Selection of the surgical methods of lower lip reconstruction

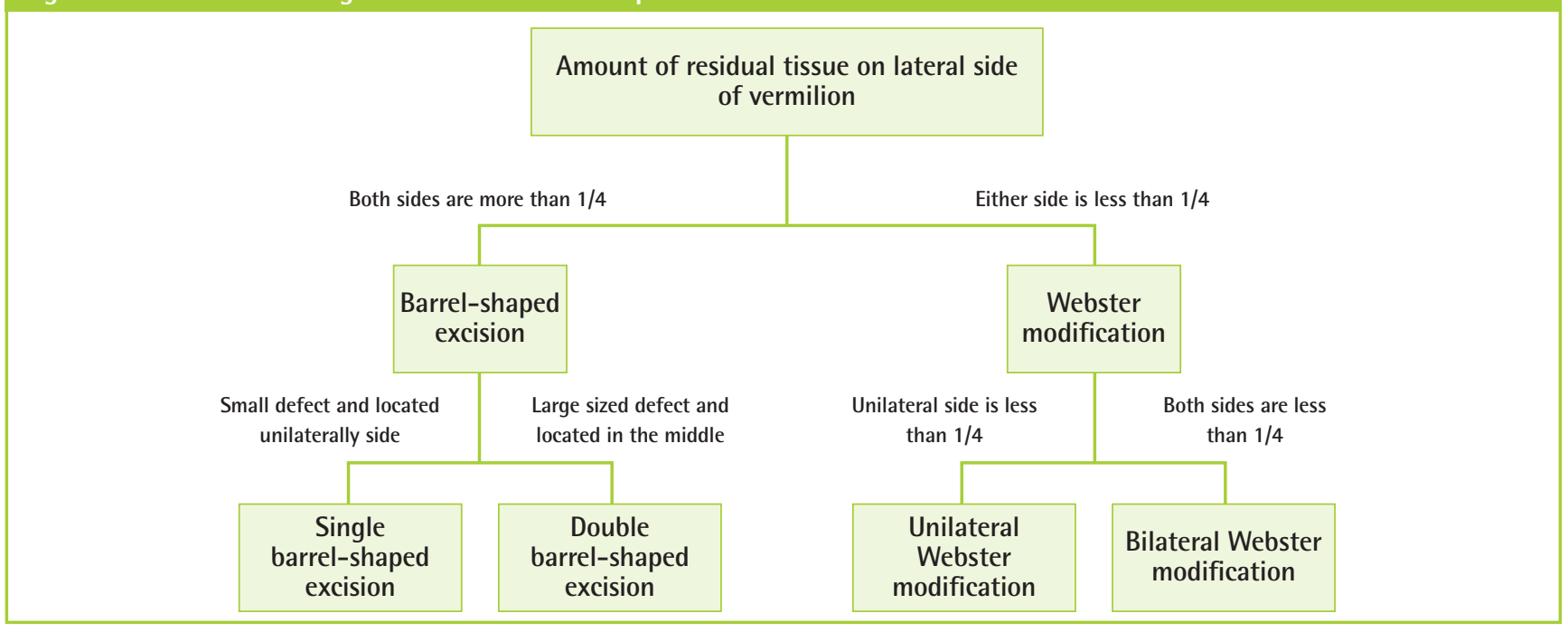

postoperative complications.

\section{Surgical techniques}

First, the surgical margin was placed at $1 \mathrm{~cm}$ away from the lower margin of the lesion and at the point on the vermilion $5 \mathrm{~mm}$ away from the left and right margin of the lesion. Subsequently, a frozen biopsy of the surgical margin was performed. If there were no tumor cells at the surgical margin, an excision was then performed according to the design. Otherwise, a frozen biopsy was performed again at $5 \mathrm{~mm}$ laterally from the previous surgical margin. If there were no tumor cells, the corresponding point was determined to be the new surgical margin for excision. We then performed a full-layer excision with the normal tissue.

In choosing the surgical method, we considered the amount of residual tissue on the lateral side of the vermilion following excision, the location of the defect, and the size of defect. If there was enough residual tissue (more than 1/4) on both of the lateral sides of the vermilion, we chose the barrel-shaped excision. In the cases of small defects located on a unilateral side of the lip, we chose to perform a single barrel-shaped excision. A double barrel-shaped excision was performed in the cases of large defects or defects in the middle of the lower lip, regardless of their size. If there was not enough residual tissue (less than $1 / 4$ ) on the two lateral sides of the vermilion, we chose the unilateral or bilateral Webster modification, considering the location or amount of residual tissue. In the cases with residual tissue on the unilateral side of the vermilion, the unilateral Webster modification was chosen, and in cases with little residual tissue on both sides of the vermilion, the bilateral Webster modification was chosen (Fig. 1). We usually followed our treatment strategy as mentioned above, but there were some exceptions depending on the patients' skin laxity elasticity and their personal preference.
In the cases in which we selected a barrel-shaped excision, we designed a procedure for a barrel-shaped excision on the labiomental fold. We then excised a full layer of the lower lip according to the design. This was followed by sufficient bleeding control. We then primarily closed the orbicularis oris muscle, mucosa, and skin on a layer-by-layer basis. When we selected the Webster modification, we minimized the muscle dissection to the lateral side and then dissected the redundant skin and soft tissue. In the reconstruction of the vermilion using the oral mucosa, the surgical site was sutured to prevent the occurrence of a vermilion notching deformity.

\section{RESULTS}

In a total of 26 patients, the reconstruction was successfully achieved using either a barrel-shaped excision or the Webster modification. Three patients underwent a single barrel-shaped excision, and nine patients underwent a double barrel-shaped excision. In addition, the unilateral Webster modification was performed for six patients, and there were eight cases of bilateral Webster modification (Table 2). All of the patients except one were satisfied with the postoperative shape of the lip. In one case, both recurrence and dehiscence occurred. Among two patients who underwent radical neck dissection, one had neck metastasis. This patient underwent revisional surgery after chemotherapy and radiotherapy at the Department of Otorhinolaryngology of our hospital. In addition, 1 patient had a good postoperative shape of the lip, but had difficulty wearing a denture, and also underwent commissuroplasty. Furthermore, there were two patients who complained of drooling and four patients with paresthesia (Table 3). 


\section{Case 1}

A 47-year-old man visited our hospital presenting with a 4-month history of a persistent lip wound, and the patient was diagnosed with squamous cell carcinoma. The patient was expected to have less than $1 / 4$ of the right side vermilion tissue remaining after excision. However, the patient wanted the most minimally invasive method possible. Therefore, in an exception to our regular procedure, we performed a single barrel-shaped excision. During the 4-year postoperative follow-up period, the patient was satisfied with the outcome and had no notable complications other than scars on the surgical sites (Fig. 2).

\begin{tabular}{|c|c|}
\hline Characteristic & Patients (\%) \\
\hline Barrel-shaped excision & $12(46)$ \\
\hline Single & $3(11)$ \\
\hline Double & $9(35)$ \\
\hline Webster modification & $14(54)$ \\
\hline Unilateral & $6(23)$ \\
\hline Bilateral & $8(31)$ \\
\hline Total & $26(100)$ \\
\hline
\end{tabular}

\section{Case 2}

A 49-year-old man had a small wound that developed on the lower lip five months before visiting our hospital. The small wound had not healed and even gradually enlarged, which eventually led to ulceration. The patient visited the outpatient clinic of the Department of Dermatology of our hospital, and was diagnosed with squamous cell carcinoma. His expected residual tissue after excision was more than $1 / 4$ on both sides of the vermilion, and the defect had occurred on the middle of the lip.

\begin{tabular}{|c|c|c|c|c|}
\hline \multirow{2}{*}{ Problem } & \multicolumn{2}{|c|}{$\begin{array}{l}\text { Barrel-shaped } \\
\text { excision }\end{array}$} & \multicolumn{2}{|c|}{$\begin{array}{c}\text { Webster } \\
\text { modification }\end{array}$} \\
\hline & Single & Double & Unilateral & Bilateral \\
\hline Recurrence & - & - & - & 1 \\
\hline Metastasis & - & - & 1 & - \\
\hline Complications & - & - & - & - \\
\hline Dehiscence & - & - & - & 1 \\
\hline Problem wearing denture & - & - & - & 1 \\
\hline Drooling & - & - & - & 2 \\
\hline Sensation problem & - & 2 & - & 2 \\
\hline
\end{tabular}

\section{Fig. 2. A case of single barrel-shaped excision}

A patient whose lip was reconstructed with an advancement after a single barrel-shaped excision. (A) A preoperative photograph. (B) The preoperative design. (C) An immediate postoperative photograph. (D) A photograph at follow-up on postoperative year 4.
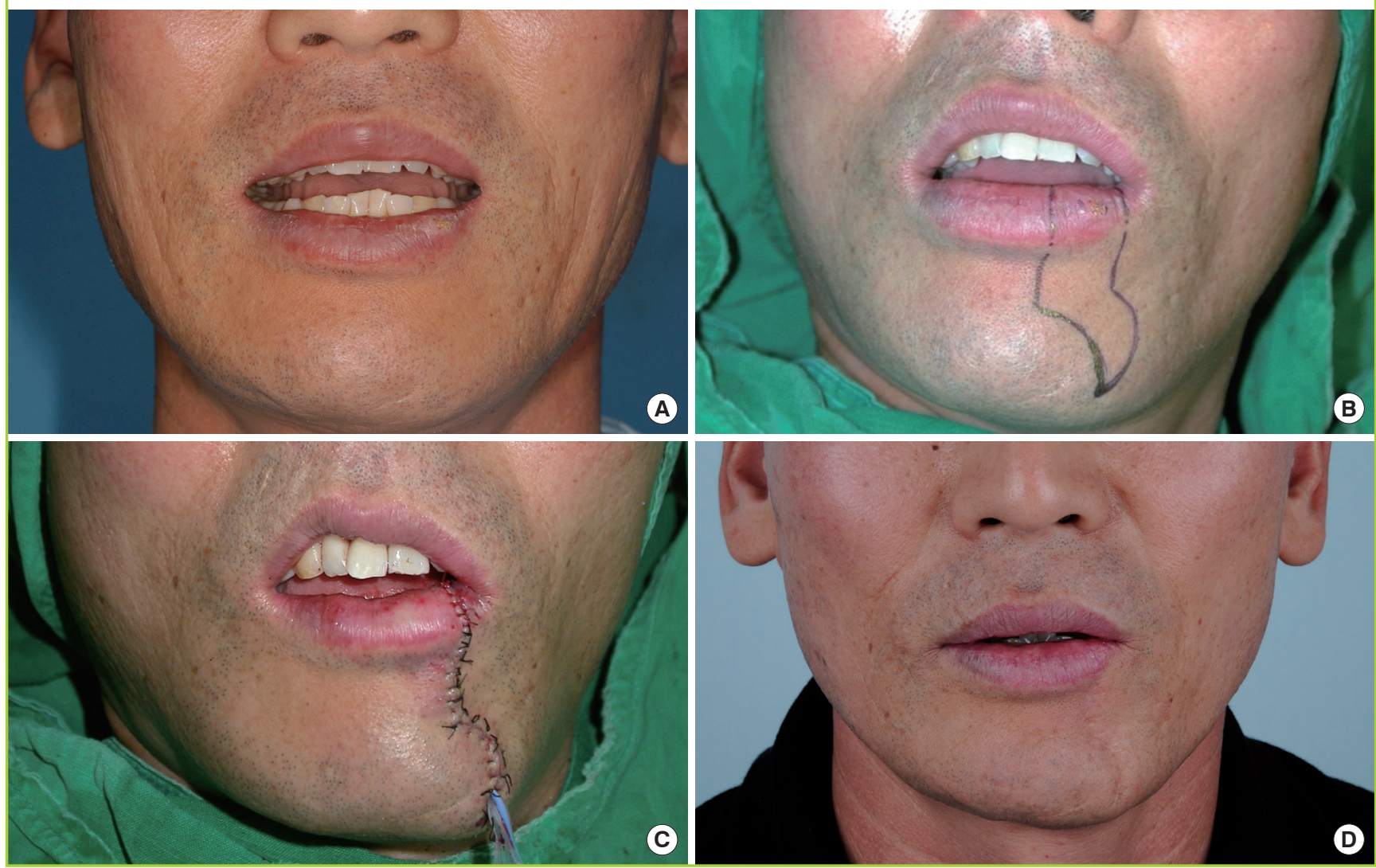


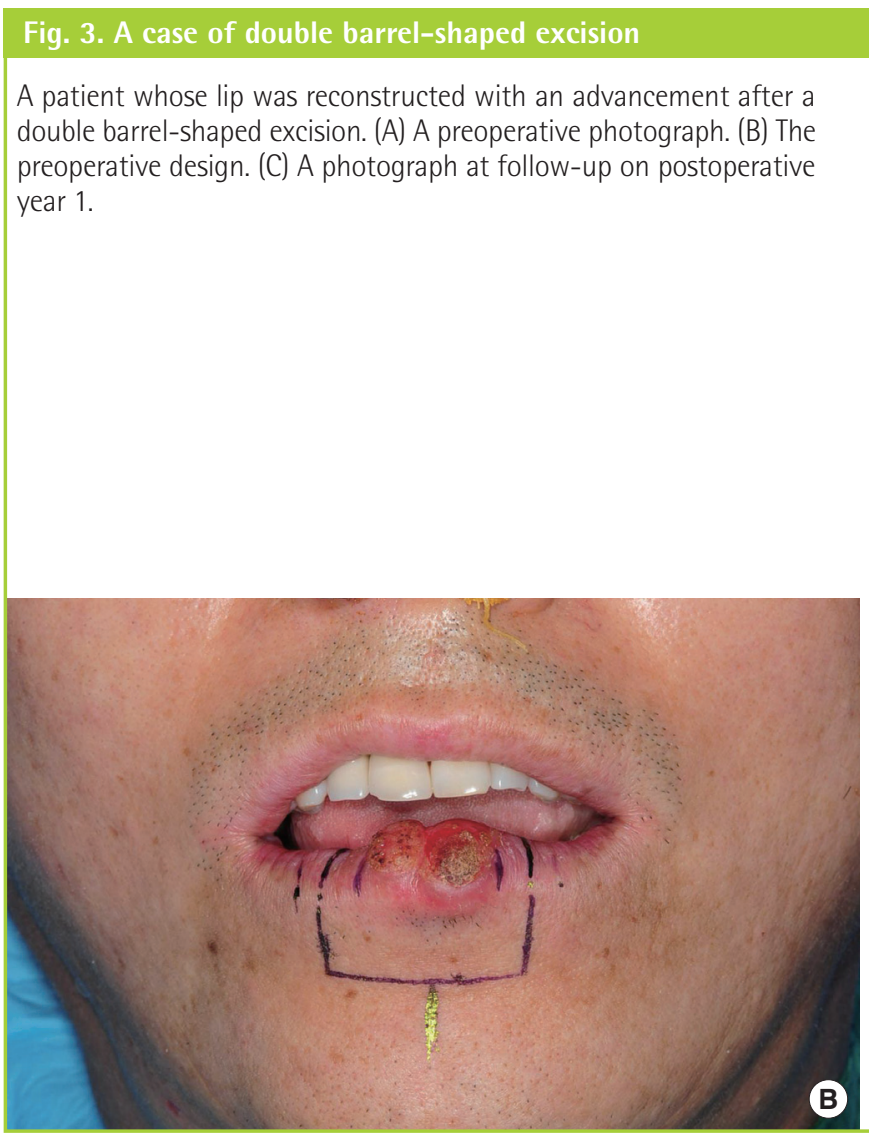

Therefore, we performed a double barrel-shaped excision. During the 1-year postoperative follow-up period, the patient was very satisfied with the postoperative outcome, and no notable complications developed (Fig. 3).

\section{Case 3}

A 77-year-old man had a persistent wound that waxed and waned on the lower lip for 7 months. The patient underwent a biopsy at the Department of Dermatology of our hospital, and the lesion was diagnosed as squamous cell carcinoma. The patient was then referred to the authors for treatment. Almost no left vermilion tissue (less than $1 / 4$ ) was expected to remain after excision, but some of the right vermilion tissue (more than $1 / 4$ ) was expected to remain. Therefore, the patient underwent the left unilateral Webster modification of the Bernard operation. On the preoperative CT scans of the neck, the patient had neck lymph node involvement in the left submandibular region. The patient additionally underwent neck lymph node dissection at the Department of Otorhinolaryngology of our hospital after reconstruction surgery. The patient had excellent treatment outcomes of the lower lip. After 4 months, however, metastasis of the left neck region was detected. Therefore, the patient had to undergo an additional operation at the Department of Otorhinolaryngology of our institution. Chemotherapy and radiotherapy were also
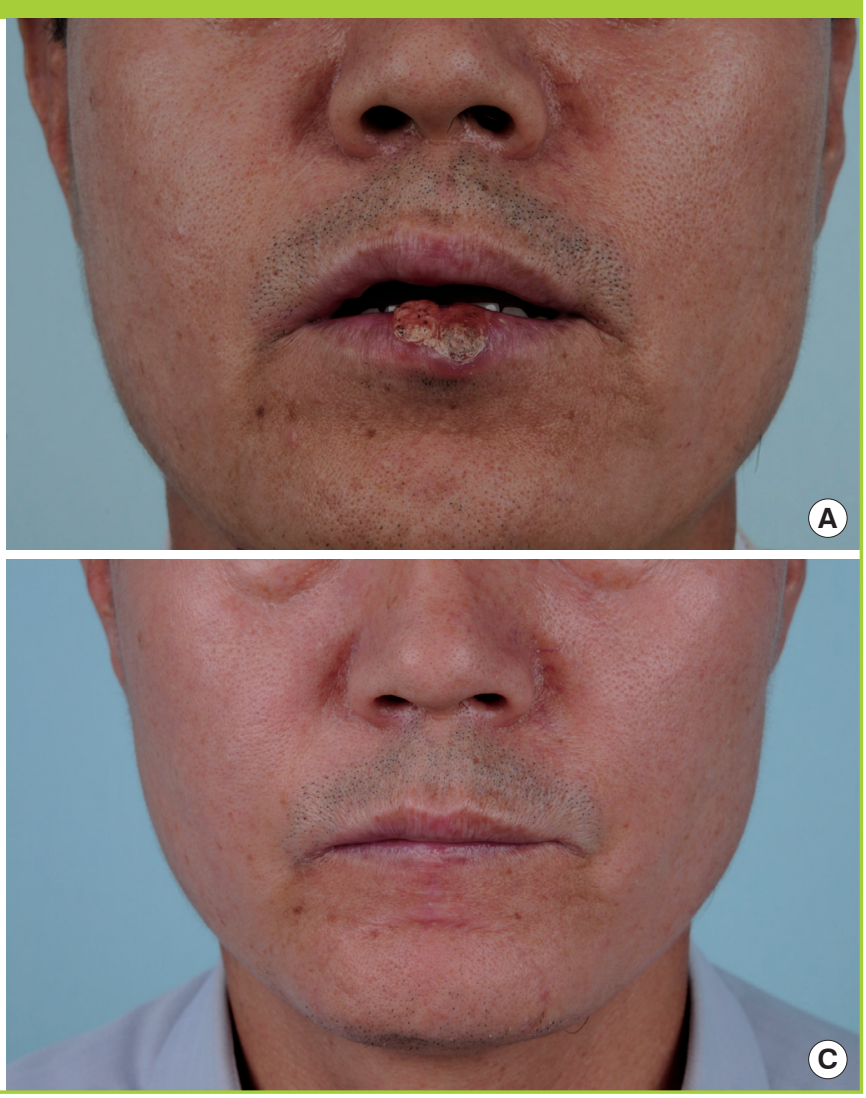

performed (Fig. 4).

\section{Case 4}

A 74-year-old woman had a history of previous excision a year before at a local clinic of a papule that had appeared 3 years earlier on the lower lip. The patient visited the outpatient clinic of our hospital with a recurred lesion. Almost no vermilion tissue (less than 1/4) on both sides was expected to remain after excision. The bilateral Webster modification of the Bernard operation was chosen. During the 12-year postoperative followup period, the patient showed good functional and cosmetic treatment outcomes. In addition, the patient had no recurrent episodes (Fig. 5).

\section{DISCUSSION}

It is known that more than $95 \%$ of tumors occurring on the lip area are located on the lower lip. Most of these cases are known to be squamous cell carcinoma [5]. Various procedures have been introduced for reconstruction after wide excision of squamous cell carcinoma on the lower lip. Each method has its own advantages and disadvantages; therefore, in choosing the optimal surgical method, a surgeon must consider the age of the patient, the size of the remnant tissue after resection, and the shape of the 


\section{Fig. 4. A case of a unilateral Webster operation}

A patient who was reconstructed using the unilateral Webster operation. (A) A preoperative photograph. (B) The preoperative design. (C) An immediate postoperative photograph. (D) A photograph at follow-up on postoperative year 1.
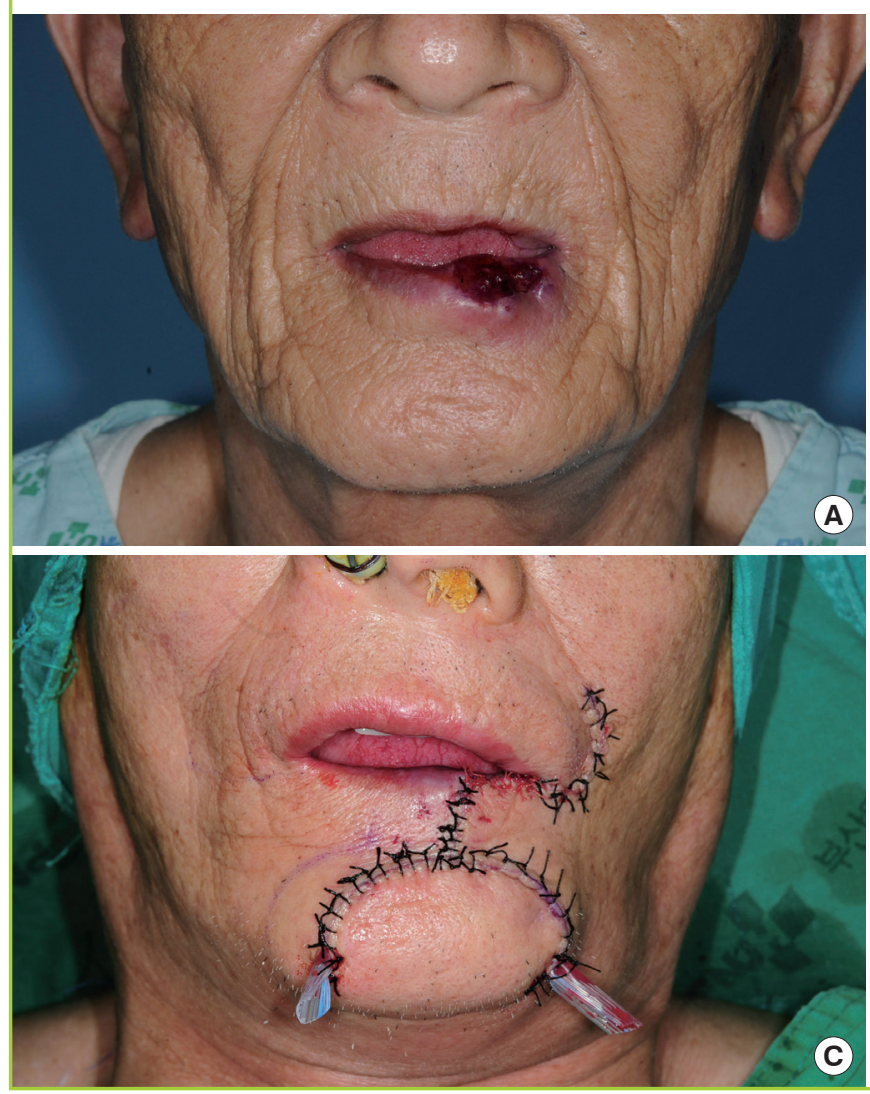

defect. In addition, for good functional and cosmetic results, surgeons should also consider the maintenance of the sensory and motor functions of the lower lip, the formation of an adequate amount of labial tissue, and the reconstruction of the vermilion to the natural shape.

The primary suture following the excision, commonly used as a relatively simpler method, has been reported to be used for small defects, specifically, those that are smaller than $1 / 3$ of the lower lip $[6,7]$. These excision methods include V-shaped excision, $\mathrm{W}$-shaped excision, flared $\mathrm{W}$-plasty, and barrel-shaped excision. It is uncommon to choose a V-shaped excision or a $\mathrm{W}$-shaped excision because the scars that form vertically to the labiomental fold can easily lead to the formation of hypertrophic scars, and the degree of tension would be higher in the upper part of the lower lip, leading to relatively poor cosmetic and functional outcomes. Flared W-plasty can be applied only to centrally-located lesions. Therefore, a barrel-shaped excision has been used more frequently because of its advantages. Excision of a tumor mass can be performed properly using a barrel-shaped excision, considering the fact that tumor cells usually invade inferolaterally in the lower lip, and the method can also be used
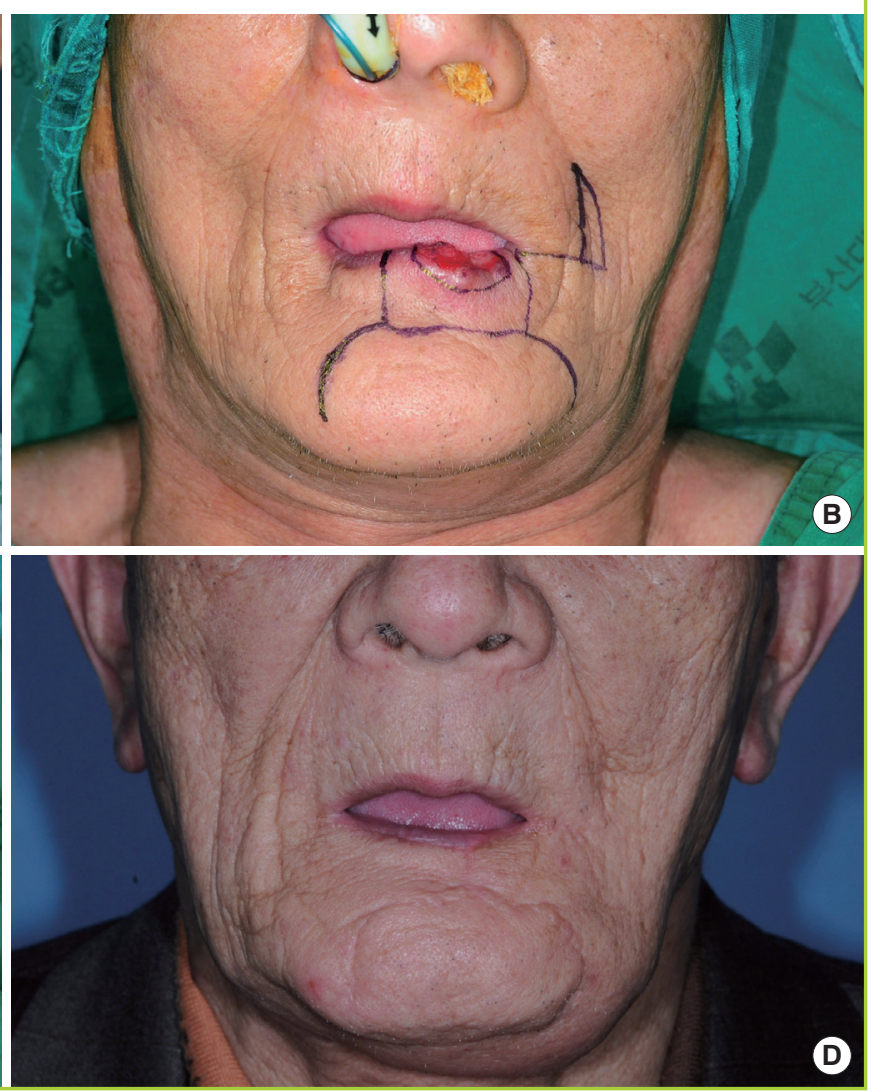

even in cases in which the lesions are not centrally located. Lee et al. [8] reported that the barrel-shaped excision could be performed for up to $1 / 2$ of the lower lip depending on the age of the patient and the degree of tension in the lower lip.

The cross-lip flap (the Abbe flap) can contribute to good functional outcomes because it can be performed without any destruction of the oral commissureIt also has some cosmetic advantages because the natural shape of the vermilion can be reconstructed. However, it has the disadvantages that second stage surgery is necessary and there is a high risk of developing a microstomia in cases of large defects [3]. A transposition flap using the depressor anguli oris muscle is a preferred method for large defects that need to be reconstructed because it preserves the functions of the oral commissure. However, the outcomes are not so great compared to those of the cross-lip flap, and the reconstruction of the vermilion is actually not cosmetically satisfying $[3,9]$. A rotational flap using the tissue of the upper and lower lips, including the Gillies fan flap, the Karapandzic method, the McGregor method, or the Nakajima method, is useful for preservation of oral commissure function, but the location of the oral commissure can be altered in an extensive reconstruc- 


\section{Fig. 5. A case of a bilateral Webster operation}

A patient who was reconstructed using the bilateral Webster operation. (A) A preoperative photograph. (B) The preoperative design. (C) An immediate postoperative photograph. (D) A photograph at follow-up on postoperative year 12 .
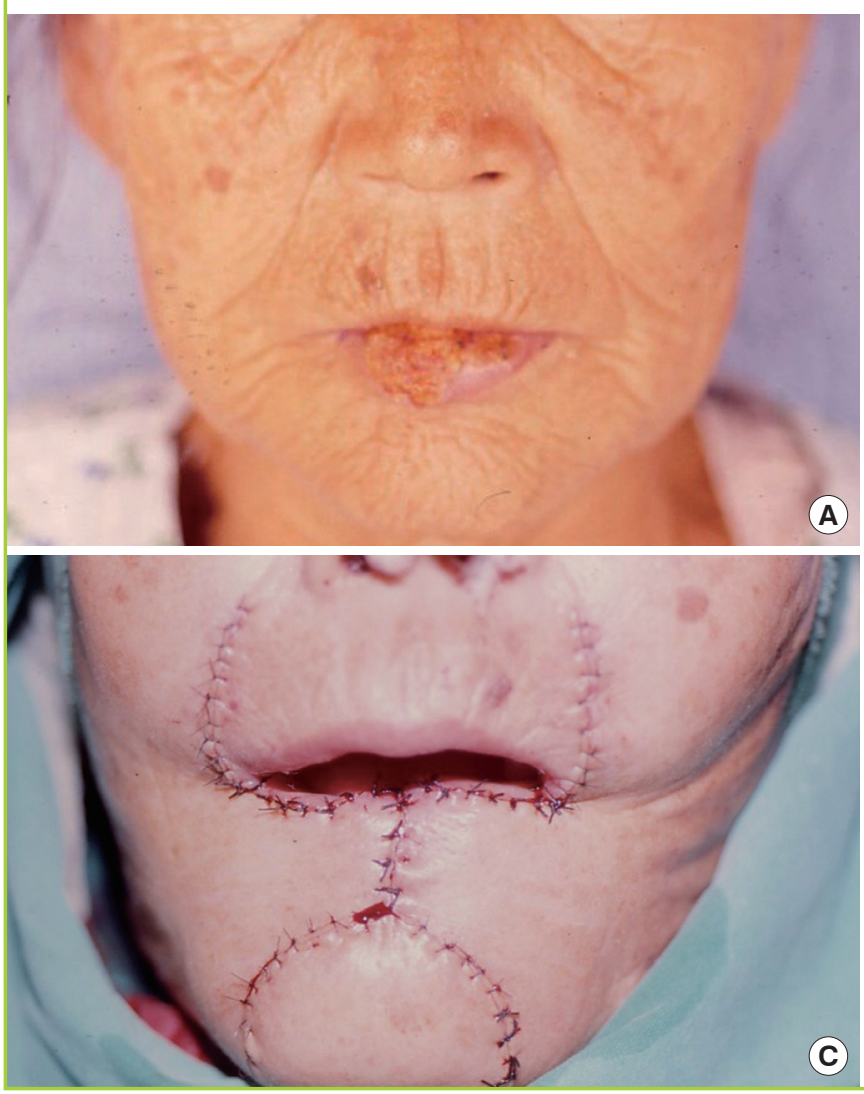

tion of the lower lip. In some cases, secondary commissuroplasty may be needed [3]. A transposition flap using the tissue around the nasolabial fold, including the Fujimori gate flap or unilateral gate flap, is useful for preserving the residual tissue of the upper lip. However, it is not easy to achieve sufficient functioning of the oral commissure and to reconstruct the vermilion to a natural shape $[3,10]$. A radial forearm free flap is a method that can be used for cases of extensive defects in the lower lip when there is a concurrent defect in the adjacent bony structures. Postoperative flap atrophy might occur in the lower lip and the contour of the lower lip cannot be reconstructed to a satisfactory degree. There also can be some difference in the skin color between the donor and recipient sites [6].

A buccal advancement flap, including the Bernard operation or the Webster modification, is useful for obtaining excellent functional (the preservation of the functions of the oral commissure) and cosmetic outcomes after reconstruction of larger defects $[11,12]$. Because it is necessary to remove the normal tissue, however, its use should be limited to only patients with redundant skin on the buccal region. Besides, this flap is also disadvantageous because the degree of tension in the lower lip
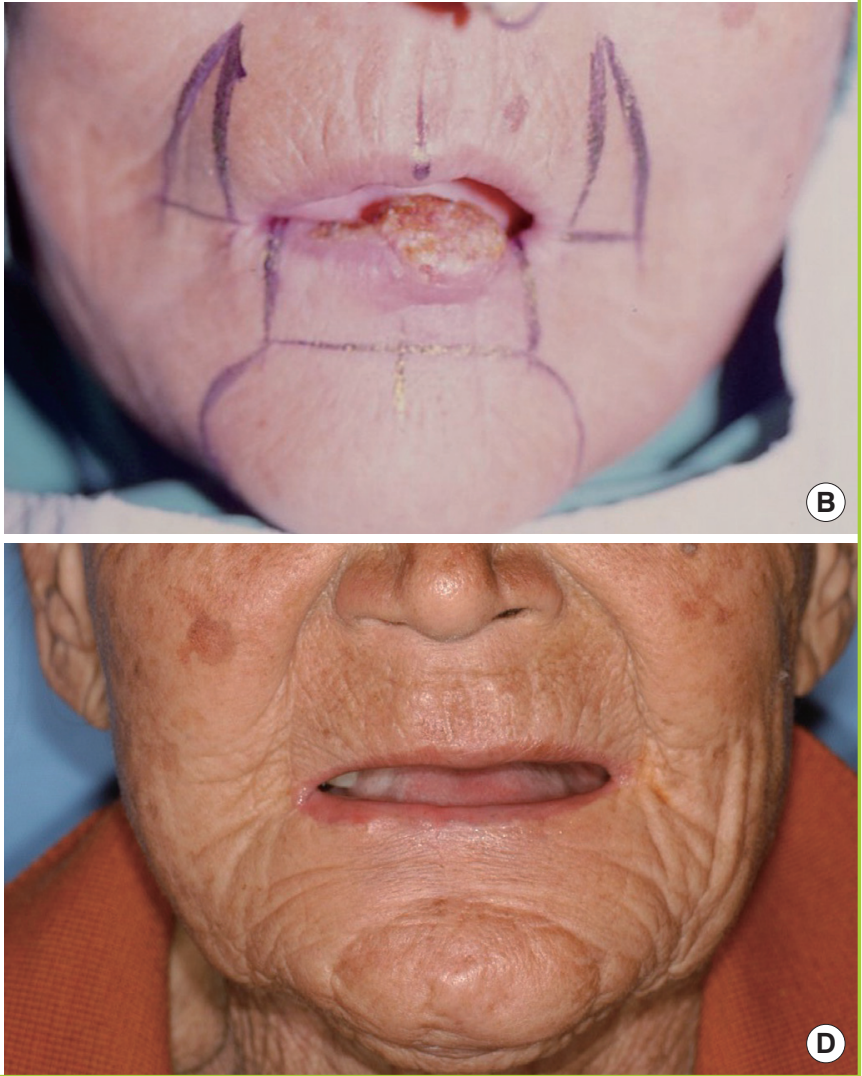

might be increased. In reconstruction of the lower lip, however, recovery of the sensation and function of the oral commissure should be considered of prime importance so that patients can maintain their daily lives without any discomfort or inconvenience. Therefore, surgeons should select a surgical procedure that preserves the sensory nerve as much as possible and that maintains the function of the oral commissure. Considering this, we have speculated that the Webster modification of the Bernard operation might be a procedure that preserves the sensory nerve as much as possible and maintains the function of the oral commissure, not only because its use is limited to the skin and subcutaneous tissue, but also because it can minimize the dissection of muscle. Therefore, we have used this procedure in extensive reconstruction of the lower lip.

We applied only two surgical methods, a barrel-shaped excision and the Webster modification, to all of the patients with a lower lip malignancy who visited the outpatient clinic of our medical institution from September 1996 to September 2010. Of these, 12 patients underwent a barrel-shaped excision and 14 underwent the Webster modification. Among them, 25 patients underwent our surgical strategy as mentioned above, with the 
exception of one patient who underwent a different procedure due to the patient's request and condition.

Of the patients, one patient had a recurrence. This patient visited our institution following the recurrence after undergoing primary surgery at a local clinic. The patient underwent a bilateral Webster modification at our medical institution. During the follow-up period, however, the patient had tooth protrusions that continuously compressed the suture line and had excessive tension exerted on the lower lip because of the previous surgery. Two months postoperatively, the patient developed dehiscence. Therefore, the patient underwent one revisional surgery. Approximately eight days postoperatively, the patient had dehiscence at the surgical sites. The patient then underwent revisional surgery again. Four months postoperatively, the patient showed a recurrence of a malignancy at follow-up, but the patient refused to undergo another revisional surgery.

In addition, 1 patient had metastasis and was suspected of having neck lymph node involvement based on the CT scans of the neck that were taken preoperatively. Therefore, the patient underwent a bilateral neck dissection at the Department of Otorhinolaryngology of our hospital. At the 4-month followup, however, the patient had a palpable mass detected in the left side of the neck. Therefore, after undergoing chemotherapy and radiotherapy at the Department of Otorhinolaryngology of our hospital, the patient received revisional surgery.

In addition, one patient had a good lip shape following reconstruction, but this patient had difficulty wearing a denture in both the maxilla and mandible; therefore, the patient additionally underwent commissuroplasty. After experiencing this case, before performing reconstruction, we examined whether there were any problems with a denture in the operative fields of all the patients who wore a denture. Accordingly, no other patients had difficulty wearing a denture.

There were four patients who experienced poor sensation. These patients were previously treated with Webster modification at our institution. As our surgical experiences accumulated, we confirmed the running of the sensory nerve fibers and preserved it as much as possible. Therefore, of those who have recently undergone the Webster modification, no patients complained of any problems with sensation.

There are various methods of reconstruction following the excision of a lower lip malignancy. However, we applied only one of two surgical methods, a barrel-shaped excision or the Webster modification, according to the surgical strategy already men- tioned, to all the patients with a lower lip malignancy. Therefore, we successfully reconstructed the lower lip in all of the patients. Moreover, the treatment outcomes were also functionally and cosmetically satisfactory. These results might be of great help for surgeons for selecting the optimal surgical modality for reconstruction of the lower lip.

\section{REFERENCES}

1. Brusati R. Reconstruction of labial commissure by a sliding U-shaped cheek flap. J Maxillofac Surg 1979;7:11-4.

2. Mazzola RF, Lupo G. Evolving concepts in lip reconstruction. Clin Plast Surg 1984;11:583-617.

3. Zilinsky I, Winkler E, Weiss G, et al. Total lower lip reconstruction with innervated muscle-bearing flaps: a modification of the Webster flap. Dermatol Surg 2001;27:687-91.

4. Wechselberger G, Gurunluoglu R, Bauer T, et al. Functional lower lip reconstruction with bilateral cheek advancement flaps: revisitation of Webster method with a minor modification in the technique. Aesthetic Plast Surg 2002;26:423-8.

5. Bae YC, Kim SH, Hwang SM, et al. Treatment of squamous cell carcinoma on lower lip. J Korean Soc Plast Reconstr Surg 1998;25:278-85.

6. Luce EA. Reconstruction of the lower lip. Clin Plast Surg 1995;22:109-21.

7. Coppit GL, Lin DT, Burkey BB. Current concepts in lip reconstruction. Curr Opin Otolaryngol Head Neck Surg 2004;12:281-7.

8. Lee TJ, Kim TJ, Park JP. Lower lip reconstruction with barrel-shaped excision. J Korean Soc Plast Reconstr Surg 1997; 24:1425-30.

9. Yotsuyanagi T, Nihei Y, Yokoi K, et al. Functional reconstruction using a depressor anguli oris musculocutaneous flap for large lower lip defects, especially for elderly patients. Plast Reconstr Surg 1999;103:850-6.

10. Alic B, Gurel M, Cilengir M, et al. Unilateral gate flap for reconstruction of the lower lip. Plast Reconstr Surg 1989; 84:814-9.

11. Rudkin GH, Carlsen BT, Miller TA. Nasolabial flap reconstruction of large defects of the lower lip. Plast Reconstr Surg 2003;111:810-7.

12. Webster RC, Coffey RJ, Kelleher RE. Total and partial reconstruction of the lower lip with innervated musclebearing flaps. Plast Reconstr Surg Transplant Bull 1960;25:360-71. 